\title{
THE ECOLOGY AND CONSERVATION MANAGEMENT OF THE PTUNARRA BROWN BUTTERFLY OREIXENICA PTUNARRA (LEPIDOPTERA; NYMPHALIDAE; SATYRINAE) IN TASMANIA, AUSTRALIA
}

\author{
by Mark G. Neyland \\ (with one table and four text-figures)
}

\begin{abstract}
Neyl.And, M.G., 1993 (31.viii): The ecology and conservation management of the ptunarra brown butterfly Oreixenica ptunarra (Lepidoptera; Nymphalidae; Satyrinae) in Tasmania, Australia. Pap. Proc. R. Soc. Tasm. 127: 43-48.

https://doi.org/10.26749/rstpp.127.43 ISSN 0080-4703. Parks and Wildlife Service, Department of Environment and Land

Management, GPO Box 44A, Hobart, Tasmania 7001.

The ecology and conservation status of the rare Tasmanian endemic butterfly Oreixenica ptunarra Couchman was investigated over a threeyear period. One hundred and fifty colonies of the butterfly have been located in areas of Poa-dominated native grassland across central Tasmania. Most colonies are small and all are under pressure from continuing stock grazing. Without active intervention the species will continue to decline. A recovery plan for the butterfly has been written, implementation of which will commence in March 1993.

Key Words: butterflies, Oreixenica, Tasmania, insects, conservation.
\end{abstract}

\section{INTRODUCTION}

The endemic ptunarra brown butterfly Oreixenica ptunarra (Couchman) is the most recently described new species from Tasmania (Couchman 1953). Three subspecies of the butterfly have been named; $O$. p. ptunarra, the smallest and darkest of these, occurs in the Central Region (biogeographic regions follow those of the Tasmanian Forestry Commission [Orchard 1988]); O. p. roonina, the largest and brightest subspecies, is found in the Centre and the Southern Midlands; O. p. angeli, which is intermediate in size and colour to the other two, occurs on the East Coast and Tiers (Couchman 1953).

By the 1980s it was recognised that the species was in decline and, following a study by Prince (1988), who found that it had suffered significant habitat loss and disturbance, the species was listed as endangered (following the IUCN Red Data Book definitions in Wells et al. 1983). This paper presents the results of a three-year study into the ecology and conservation needs of this butterfly. The aim of the study was to identify the habitat of the butterfly, the extent and condition of its remaining habitat, its distribution and the threats to its continuing survival.

\section{METHODS}

\section{Distribution and Site Studies}

Prince (1988), identified 33 locations for the butterfly from the records of other collectors, in particular, L. Couchman and G. Ellis. Following a study of these sites and the identification of a potential habitat profile, a register of potential sites was developed based on the known sites, air photo interpretation and field surveys. Additionally, around 150 potential sites from a recent survey of native grasslands in Tasmania (Kirkpatrick et al. 1988), fell within the range of the butterfly, giving a total of over 400 potential sites. The floristics, altitude, slope, aspect, geology, soil type, topographic position, bare ground (\%), relative cover of native versus introduced vegetation, Poasp. cover (\%), vegetation structure, fire history, grazing history and recent management history, including significant disturbance events, were recorded at every site. An estimate of solar radiation based on the horizon angle was also recorded.

\section{Population Surveys}

As many sites as possible were visited during the short flight season, and the presencer and relative abundance of the butterfly were recorded. Formal counts, after the method of Pollard (1977), were made whenever possible. These counts involved walking through a butterfly colony along a random route and counting all butterflies observed over a twentyminute period. Counts were only conducted under good weather conditions (light winds and over $18^{\circ} \mathrm{C}$ ). The earliest and latest dates that the butterfly was observed from each biogeographical region was recorded.

\section{Larval Food Plant}

Larvae were collected from a numbet of sites in order to identify the larval food plants and to attempt captive rearing.

\section{Conservation Status}

An assessment of the conservation status of each site was made on the basis of the size of the site, the health and abundance of tussock grass (Poaspp.), the observed numbers of butterflies and the land tenure of the site. Sites were rated on a favourability scale of $1-3$. Those sites which are in excellent condition, show no indication of disturbance by European occupation, are large in area and are rich in butterflies were rated " 1 ". Sites rated " 3 " are those where the butterfly appears likely to become extinct in the near future. Sites rated " 2 " are intermediate.

\section{Data Analysis}

The floristic data were stored on a mainframe computer and manipulated using DECODA (Minchin 1990). The floristics were initially analysed using DECORANA (DCA) (Hill \& Gauch 1980) and TWINSPAN (Hill 1979). The ordination (DCA) scores were then analysed against the various site factors, using Pearsons product moment correlation analysis 
to identify which factors, if any, were related to the DCA scores, and hence to determine which factors were important with respect to the distribution of the butterfly.

\section{Climatic Profile}

The computer program BIOCLIM (Busby 1986a, Nix 1986) was used to explore the extent to which the distribution of the butterfly is related to climatic factors. BIOCLIM calculates a climatic profile for a species based on 16 different climatic parameters, such as the mean temperature of the coolest month, the mean temperature of the warmest quarter and so on. The climate profile was calculated separately for each of the three subspecies. Subspecies O.p. roonina was further subdivided into the Midlands colonies and those from the Northwest Plains, as it was considered likely that the two areas would have differing climatic profiles. The profile of the species as a wholewasalso examined. BIOCLIMalso calculates a predicted distribution for the species, based on the correlation between the known distribution and the climatic profiles of points outside the known range of the species. Points which fail to match all 16 parameters within the total climatic range of the species are not plotted. Points which match all 16 parameters within the total range are plotted as "-"; points which match all 16 parameters within the 90 percentile range (5-95\%) as "+"; points which match 13-15 of the parameters within the interquartile range $(25-75 \%)$ as "Ø"; points matching all 16 parameters within the interquartile range as "\$" (Busby 1986b). In other words, the program indicates where there are areas with climates which closely match the climate of the known range of the species. Experience suggests that the points labelled “+", " $\emptyset$ ", or " $\$$ " are the most likely predictors of suitable areas.

\section{RESULTS}

\section{Distribution}

The range of the butterflyextends over three biogeographical regions within the State, the Centre, the Southern Midlands and the East Coast and Tiers (Orchard 1988). The Centre is divided here into three subregions, the northwestern portion (that part of the Centre region north and west of Cradle Mountain), being referred to hereafter as the Northwest Plains, the central portion being referred to as the Central Plateau and the southeast portion (that part of the Centre region south and east of the Steppes Historic Site), being referred to as the Steppes. O.p. ptunarra occurs only on the Central Plateau. O. p. roonina occurs on the Northwest Plains, the Steppes and the Southern Midlands, and O. p. angeli occurs on the East Coast and Tiers.

The Central Plateau region ranges from 900-1400 m a.s.l. The topography is undulating and rugged, with thousands of lakes dotting the dolerite surface. Patchy grasslands and grassy shrublands extend across the entire plateau, but whether the current vegetation resembles the preEuropean vegetation or whether the recent history of the plateau has caused significant changes to the vegetation remains the subject of much speculation (Jackson 1973). Oreixenica $p$. ptunarra was thought to occur in suitable habitat throughout the region, but the evidence from the 1992 field season suggests that the butterfly may be quite restricted in its distribution. It is now thought likely that the butterfly is restricted to the enviruns of Great Lake and Arthurs Lake and does not extend to the western Central Plateau.

The Northwest Plains is a recently discovered extension to the known range of $O$. ptunarra. The region extends north and west from the Great Western Tiers as broad ridges and plains, ranging from $500-900 \mathrm{~m}$ a.s.l. The soils are generally fertile but a combination of frosts and fire has perpetuated a mosaic of grasslands, eucalypt forests and rainforests. The vegetation pattern in the northeastern highlands is very similar and the ecological relationships there have been described in detail by Ellis (1985). In particular, regular firing by Aborigines is believed to have maintained the open grassy nature of the vegetation. The butterfly is generally found in grassy open woodland, dominated by either Eucalyptus rodwayi and/or E. delegatensis or in open grasslands dominated by Poa labillardieri.

The Steppes is a region of gently undulating, sometimes poorly drained country, ranging from $500-900 \mathrm{~m}$ a.s.l. The slopes generally support E. delegatensis dominated wet forest. Locally poorly drained areas support grassy $E$. rodwayi woodland, which still supports some large populations of the species. Grassy plains are locally extensive and, where they are not significantly altered by grazing or firing, they still support colonies of the butterfly. Recent developments in high-altitude grass species have resulted in an increase in the rate of land clearing in the area. Woodchipping operations have also had an impact on the butterfly. O. $p$. roonina is widespread through the region.

The Southern Midlands region is a lower surface of hills, gullies and plains, ranging from $250-600 \mathrm{~m}$ a.s.l. Originally the vegetation of the Midlands was a mosaic of grasslands, woodlands and open forests (Fensham 1989). Approximately $90 \%$ of the Midlands has since been converted to improved pasture (Fensham 1989). This ongoing process has had a dramatic effect on the butterfly. Throughout the Midlands, populations of the butterfly (O. p. roonina) are found only in lowland Poa labillardieri tussock grasslands.

The East Coast and Tiers extend up the central east coast of Tasmania, reaching a high point of $971 \mathrm{~m}$ at Snow Hill, but generally ranging from $0-800 \mathrm{~m}$ a.s.l. The area comprises moderately dissected dolerite hills carrying dry or wet sclerophyll forests invariably dominated by Eucalyptus species. Poorly drained areas, notably around Lakes Tooms and Leake and around the headwaters of the Macquarie River, carry grassy and/or sedgy open woodland communities, often dominated by $E$. rodwayi, in which $O . p$. angeli is occasionally found.

\section{Population Surveys}

One hundred and fifty colonies of the butterfly have been located to date, after three years of intensive searching. The Southern Midlands, the East Coast and Tiers and the Northwest Plains have been systematically searched, but it is likely that additional colonies will be discovered in the future on the Central Plateau and on the Steppes. Four colonies extant in 1988 are believed to have now become extinct. The most significant of these was that at Mike Howes Marsh, the rype locality for $O$. p. roonina.

Most extant colonies are smaller than 10 ha and only 20 colonies exceed 50 ha (fig. 1). The net area of O. ptunarra habitat is very roughly estimated at 4000 ha. Figure 2 shows the different conservation status of the various colonies. 


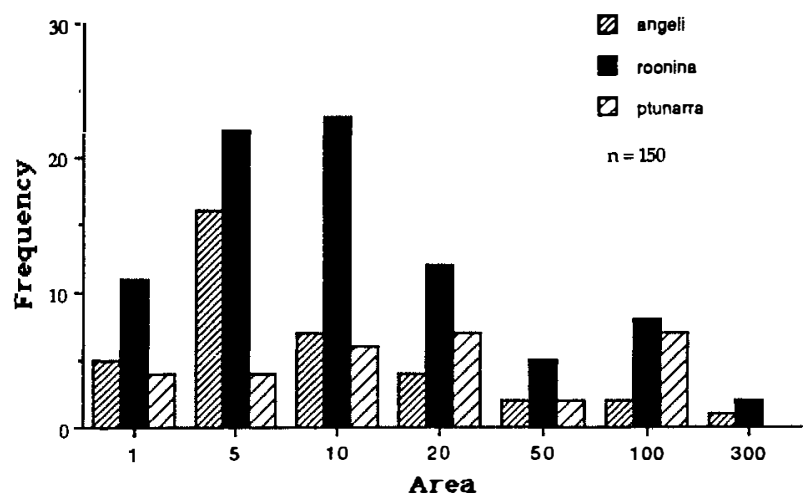

FIG. 1 - The areas of all known sites by size (ha).

\section{Life History}

The butterfly flies in autumn for about two weeks at any given site. Butterflies are usually seen in numbers only. on days of mild weather with light breezes (temperatures above $18^{\circ} \mathrm{C}$ and winds below 15 knots). Males emerge earlier than females, and upon emergence the females are soon mated. Egg-laying follows shortly after mating. The eggs are nonsticky and are simply dropped into Poa tussocks, often while butterflies are on the wing. The eggs hatch in about six weeks and the larvae feed through the winter and in to the following summer, pupating in February for four to five weeks, the imago emerging in mid to late March (Couchman 1953).

\section{Food Plant}

The larvae feed at night on the tips of Poa species (snow grasses). Four species have been identified as food plants. Larvae were collected from three species of Poa, the fourth is the only species of Poa at the site (P. clelandii) (nomenclature follows Buchanan et al. 1989) and is therefore likely to be the host plant. The four species are Poa labillardieri (var. labillardieri and var. acris), P. rodwayi, P. gunnii and $P$. clelandii. Poa sieberiana and P. hookeri were also present on some sites and may also be food plants.

\section{Flight Dates}

The times of first emergence for the different subspecies of the butterfly in each of the five biogeographical regions within its range are given in table 1 . The butterfly emerges earlier in the higher altitude regions, those on the Central Plateau emerging up to two weeks earlier than those on the Southern Midlands.

\section{Data Analysis}

The DECORANA analysis shows that the butterfly occupies a characteristic ecological niche (fig. 3). Sites circled are those from which butterflies were not recorded, those to the left being predominantly grasslands dominated by kangaroo grass, Themeda triandra, in the dry eastern Midlands, those to the right being high altitude grassy sites.

Correlation analysis of the DCA scores against the site factors shows that the first axis of the DCA is highly significantly related to altitude $(\mathrm{r}=0.8713, \mathrm{P}<0.0001, \mathrm{n}=338)$. The second axis of the DCA is significantly related to the cover of Poa $(\mathrm{r}=0.1959, \mathrm{P}<0.001, \mathrm{n}=338)$, and to the percentage of bare ground on the site $(r=0.2613, P<0.0001$,

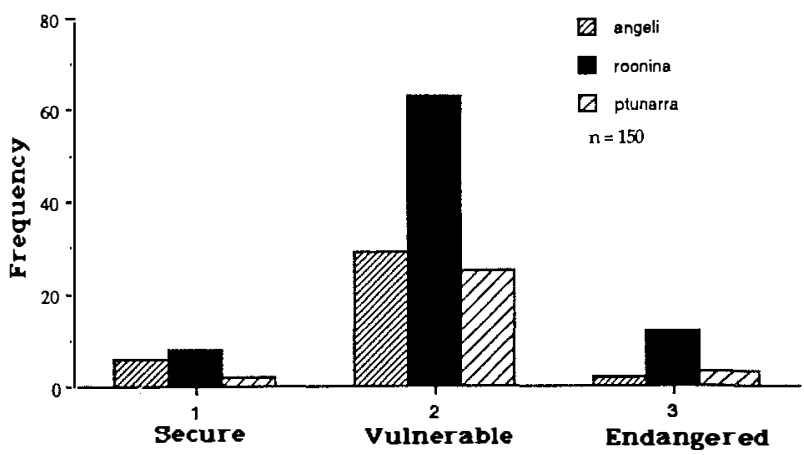

FIG. 2 - The conservation status of known colonies of each subspecies.

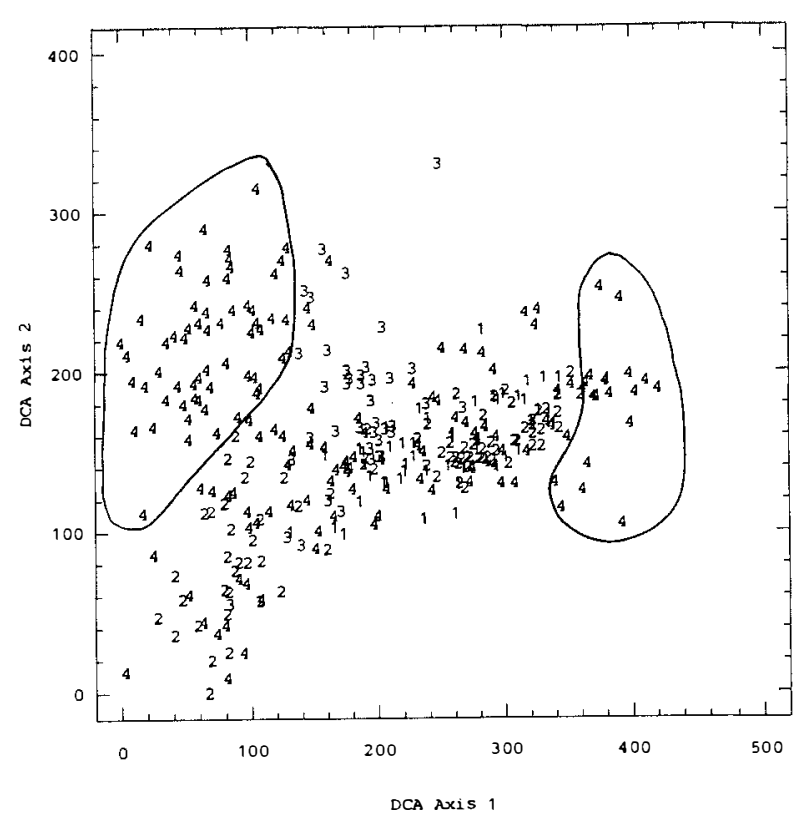

FIG. 3 - Scatterplot of all sites on the first two ordination axes. Sites labelled 1, 2 or 3 are those which carry butterflies. Sites labelled 4 do not carry butterflies.

$n=338$ ), factors which are obviously related. The presence or absence of the butterfly is significantly correlated with the cover of Poa $(\mathrm{r}=0.1999, \mathrm{P}<0.0005, \mathrm{n}=338)$.

\section{Climatic Profile}

The climatic profile, as indicated by the predicted distribution of each subspecies, is very narrow (fig. 4). With the exception of subspecies roonina in the Southern Midlands, it appears that the full potential range of each subspecies is occupied. Oreixenica p. roonina in the Southern Midlands is shown to have potential to expand to the southwest of its present range. This area no longer contains any suitable habitat, as a result of clearing and grazing pressures.

When the collective climate profile is examined, the predicted range matches the known range quite closely, with the notable exception of the northeast highlands (fig. 4). The analysis indicates that the climate in the northeast highlands is suitable, and suitable habitat is known to occur there, but searches by previous authors (Couchman 1977) in the area have failed to locate the butterfly. 
TABLE 1

Flight dates for the different regions

\begin{tabular}{|c|c|c|c|}
\hline & $\begin{array}{l}\text { First recorded } \\
\text { emergence }\end{array}$ & $\begin{array}{l}\text { Last recorded } \\
\text { emergence }\end{array}$ & Alt. range (m) (approx.) \\
\hline Central Plateau & $\begin{array}{l}\text { 12.iii.1991 } \\
\text { 5.iii.1992 }\end{array}$ & & $750-1200$ \\
\hline Steppes & $\begin{array}{c}\text { 16.iii.1990 } \\
\text { 10.iii.1991 } \\
\text { 7.iii.1992 }\end{array}$ & 4.iv. 1990 & $600-1000$ \\
\hline Northwest Plains & 10.iii.1992 & & $500-900$ \\
\hline $\begin{array}{l}\text { East Coast } \\
\text { and Tiers }\end{array}$ & $\begin{array}{l}\text { 18.iii.1990 } \\
\text { 16.iii.1991 } \\
\text { 17.iii.1992 }\end{array}$ & 30.iii.1990 & $400-800$ \\
\hline $\begin{array}{l}\text { Southern } \\
\text { Midlands }\end{array}$ & $\begin{array}{l}\text { 16.iii. } 1990 \\
\text { 23.iii.1991 } \\
\text { 17.iii.1992 }\end{array}$ & $\begin{array}{l}\text { 3.iv. } 1990 \\
\text { 7.iv.1991 }\end{array}$ & $300-750$ \\
\hline
\end{tabular}

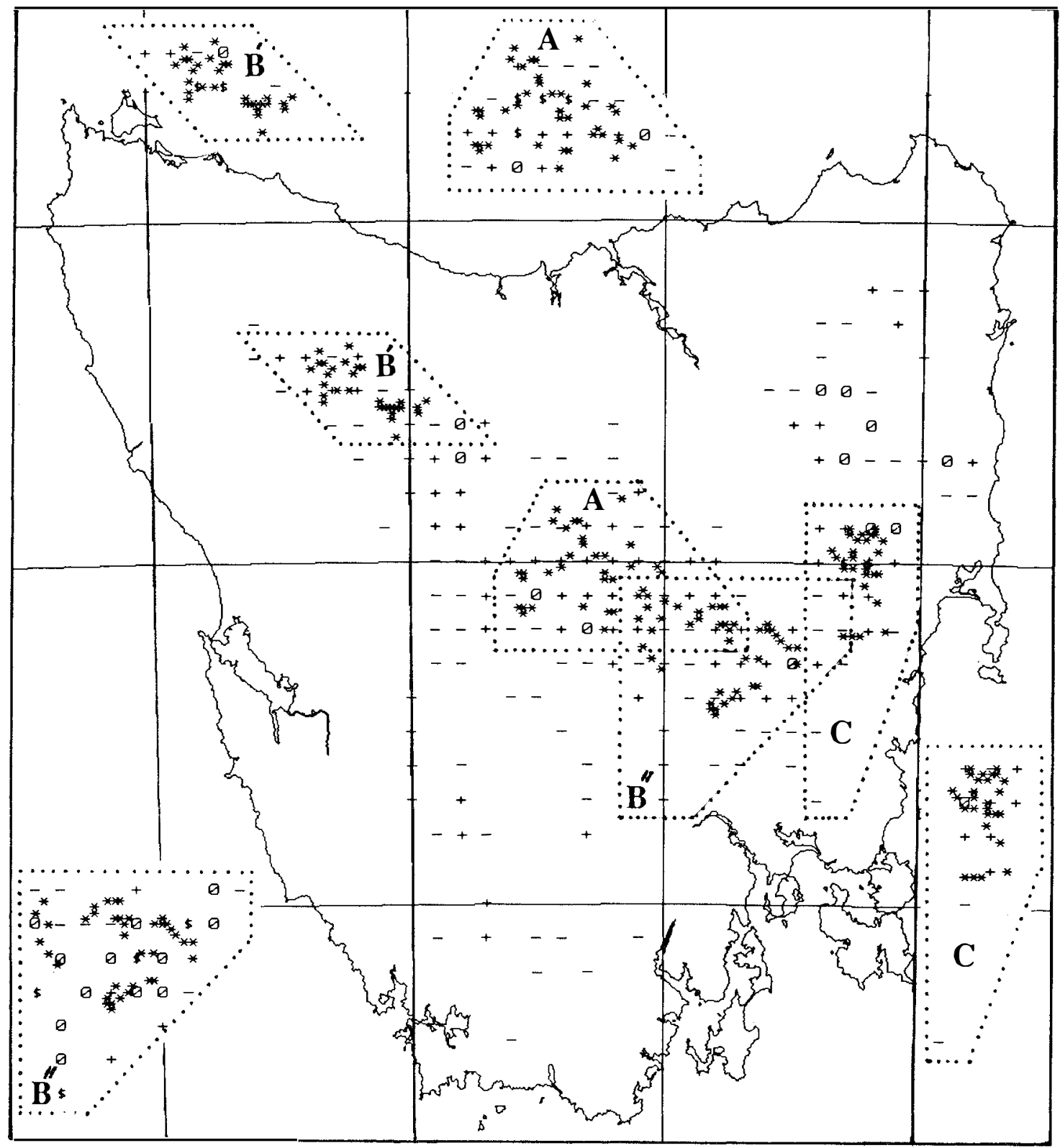

FIG. 4 - The actual and predicted (using BIOCLIM) range of Oreixenica ptunarra. The insets show the actual (asterisks) and predicted ranges of the three sub-species. Note that for O. p. roonina the predicted ranges for the Steppes and Southern Midlands and for the Northwest Plains were calculated separately A-O. ptunarra ptunarra; $B^{\prime}-$ O. ptunarra roonina, Northwest Plains; $B^{\prime \prime}-$ O. ptunarra roonina, Steppes and Southern Midlands; C - O. ptunarra angeli. 


\section{DISCUSSION}

The ptunarra brown does not extend into the drier lowland grasslands in the Northern Midlands, or into the highaltitude grasslands of the western Central Plateau. However, there are potentially suitable sites within the broader range of the butterfly that do not carry butterflies. That there are no significant floristic differences between these sites and those with butterflies suggests that the absence of butterflies may be related to the site history or to other site factors. For example, the site may have been cleared at some time in the past and has since been recolonised by tussock grasses. Although the habitat now appears suitable for the butterfly, it is possible that, in the absence of suitable habitat corridors, the butterfly is unable to recolonise such sites from nearby colonies. Some vacant sites, especially in the Southern Midlands, appear suitable for possible re-introductions of the butterfly.

The bioclimatic analysis indicates that the butterfly now occupies its full potential range, with the possible exception of the northeast highlands. Within its range, the butterfly is limited mostly by the availability of habitat. In the Northwest Plains, suitable grasslands develop only on more fertile soils, and to the west and south of the Northwest Plains, grasslands are replaced by sedgelands as basalts are replaced by less fertile parent materials. The link between the Northwest Plains and the Central Plateau has yet to be determined. That the butterfly does not extend to the western Central Plateau is puzzling, although the results of the multivariate analysis indicate that the climate may be prohibitive. It is also possible that the butterfly has been eradicated from the Central Plateau by a European history of overfiring and overgrazing. In the late 19th century, there were over 350000 sheep and 6000 cattle on the Central Plateau (Shepherd 1973). To the southwest of the Central Plateau and the Steppes regions, the butterfly is again, as in the Northwest, restricted by the availability of habitat, as vegetation changes in response to changing soils. In the Southern Midlands and the East Coast and Tiers, the butterfly was found wherever there was suitable habitat. In both regions suitable habitat is sparse.

The butterflies key requirement is a healthy cover of Poa sp. tussock grass extending over at least one hectare. The strongest colonies observed were in areas of more than 50 ha. That the butterfly is now endangered is directly related to the attrition and fragmentation of available habitat caused by land clearing.

\section{Conservation Status}

All three subspecies of the butterfly are currently considered endangered (Neyland 1992). Oreixenica p. roonina is found in three distinct regions, the Southern Midlands, the Steppes and the Northwest Plains. In 1988, only eight populations were known from the the Southern Midlands and all of these were considered endangered. Recent surveys in the Southern Midlands have located ten additional populations of the species but all are considered endangered. All suitable habitat in the region has now been surveyed, and it is considered that there is little potential for finding further colonies. Four populations have become extinct since a survey in 1988 (Prince 1988). All the existing colonies are small and grazed by sheep and/or cattle.

In the Steppes region, the butterfly is more widespread, but all colonies are subject to grazing. Grazing pressures are variable. Only one site is considered secure at present.
In the Northwest Plains region, the butterfly occupies a distinct ecological niche in grasslands and grassy woodlands. These grasslands are naturally restricted in their extent, and large areas have recently been converted to eucalypt plantation.

Oreixenica $p$. angeli is very restricted in its distribution, and is known only from grassy woodland and grassy open forest in the East Coast and Tiers. Despite a long history of overgrazing and overfiring in its habitat, O.p. angeli persists through most of its range, although numbers are low at many sites.

Prince (1988), on the basis of "a number of relatively secure populations and considerable areas of unexamined potential habitat", considered O.p.ptunarra to be secure on the Central Plateau. However, the absence of the butterfly from large areas of apparently suitable habitat suggests that the butterfly is not as widespread on the Central Plateau as previously considered. If, indeed, the butterfly is restricted to the eastern Central Plateau, then most of the Central Plateau colonies are located on private land and are sensitive to the same pressures as colonies in the Southern Midlands and elsewhere. Further fieldwork is required on the plateau before its range can be accurately defined.

\section{Land Clearing}

The species is absent from areas which have been converted to pasture (Prince 1988). Large areas which were originally native grassland and open grassy woodland in the Steppes and Southern Midlands have been cleared and converted to pasture, resulting in the loss of large areas of butterfly habitat. Many existing populations are found on the fringes of areas which would once have supported large colonies of butterflies, but where the original vegetation is now restricted to small pockets around larger areas of pasture. Native grasslands and grassy woodlands had high fertility and were easily converted to pasture, soon after the European settlement of Tasmania.

The ability of the species to recolonise areas at any distance from extant populations is unknown. The butterfly is a weak flyer, and the probability of recolonising sites, unless suitable habitat corridors exist, appears low. The long-term viability of populations that are now small remnants of once large populations is also unknown, although they are extremely vulnerable to disturbance. If small remnant populations are lost, through overgrazing or fire or clearing, then those sites may never be recolonised.

\section{Grazing}

It is difficult to assess accurately the impact of grazing, as the tussock grasses persist in all but the most heavily grazed areas. The long-term survival of the species depends upon the survival of healthy, dense $(>25 \%)$ populations of Poa. The control of stock-grazing levels on butterfly colonies is the first priority, because, without a reduction in the grazing pressure, many extant colonies will soon be extinct. Conversely, at a number of sites where there has been little or no grazing and where the tussocks have become large and overgrown, there are fewer butterflies than at nearby sites which are lightly grazed. This may be related to the apparent preference of the butterfly to fly around high tussocks rather than over them.

Long-term monitoring of a range of sites is essential in order to quantify the effects of varying grazing pressures on populations of the butterfly. 


\section{Plantation Development}

In the Northwest Plains region, large areas of Poa-dominated grasslands have recently been converted to eucalypt plantations by private timber companies. Further areas will be converted in the future. Some areas within the region have been set aside as reserves, but additional areas of grassland within the plantation program may need to be set aside as reserves for the butterfly, to prevent their local extinction.

\section{Burning}

Repeated burning of remnant native grasslands has caused severe decline in population levels in some areas, notably on private land in the East Coast and Tiers, where the traditional management practice has been to burn the grassy forests every two or three years. Anecdotal evidence suggests that in some areas the burning was annual. Burning of these forests is done to encourage "green pick" for stock. The species has persisted in these areas, although at many sites butterfly numbers are now low. A reduction in the frequency of burning is necessary to ensure the survival of the species in these areas. A pattern of mosaic burning, aimed at burning different areas each year on an approximately seven-year cycle, achieves the aim of reducing fuel loads and maintaining grassiness without a loss in productivity or understorey diversity. A longer cycle of mosaic burning would also be more suited to the butterfly.

The season of burning is also important. During the day, the larvae hides in the base of the tussock. Hot fires in summer are more likely to kill them than cooler fires in spring or autumn which leave more of the tussock base intact. Fires during the flight season (March) should be avoided entirely.

\section{CONCLUSIONS}

The current parlousstate of the butterfly is a reflection of the very poor state of most native grasslands in Tasmania (Kirkpatrick etal. 1988). In the Southern Midlandsthe original vegetation was a mosaic of grasslands and grassy woodlands (Fensham 1989). It is likely that, in the past, the butterfly would not have been restricted to small discrete patches of habitat but, rather, would have been able to roam over extensive areas, wherever tussock grasses were present. The fragmentation and degradation of habitat has caused the gradual decline of the butterfly to its present endangered state.

Fortunately tussock grass can persist, even in the face of heavy grazing, and is only eradicated completely by ploughing. In old pastures, tussock grass is able to re-establish, and some extant colonies could potentially expand simply through control of grazing in adjacent areas, which would allow the tussock grasses to spread.

A recovery plan for the butterfly has been prepared (Neyland 1991) funded by the Australian National Parks and Wildlife Service under the Endangered Species Program. This plan outlines the steps necessary to ensure the longterm survival of the species. Control of stocking rates on butterfly colonies, either through fencing or th nugh reductions in stocking rates, is the key to survival of the butterfly.

\section{ACKNOWLEDGEMENTS}

This research was funded by the Australian National Parks and Wildlife Service under the Endangered Species Program. Mick Brown, Peter Brown and Humphrey Elliot provided useful comments on an earlier draft of the manuscript. Colin Reid assisted with the BIOCLIM package and the textfigures.

\section{REFERENCES}

Buchanan, A.M., McGeary-Brown, A. \& Orchard, A.E., 1989: A CENSUS OF THE VASCULAR PLANTS OF TASMLNLA. Occ. Publ. Tasm. Herb. 2.

BuSBY, J.R., 1986a: BIOCLIMATE PREDICTION SYSTEM (BIOCLIM). USER'S MANUAL VERSION 2.O. Bureau of Flora and Fauna, Canberra, ACT.

BusBY, J.R., 1986b: A biogeoclimatic analysis of Nothofagus cunninghamii Hook. (Oerst) in southeastern Australia. Aust. J. Ecol. 11: 1-7.

CoUChMAN, L.E., 1953: Notes on some forms of Oreixenica Waterhouse and Lyell (Lepidoptera, Satyridae), with description of new forms. Proc. R. Entomol. Soc. Lond. B 22: 73-84.

ELLIS, R.C., 1985: The relationships among eucalypt forest, grassland and rainforest in a highland area in north-eastern Tasmania. Aust. J. Ecol. 10: 297-314.

FENSHAM, R.J., 1989: The pre-European vegetation of the Midlands, Tasmania: a floristic and historical analysis of vegetation patterns. J. Biogeog. 16: 29-54.

HiLl, M.O., 1979: TWINSPAN: A FORTRAN program for arranging Multivariate data in an ordered two-way table by classification of the individuals and attributes. Cornell Univ., New York.

HiLl, M.O. \& GAUCH, H.G., 1980: Detrended correspondence analysis: an improved ordination technique. Vegetatio 42 : 47-58.

JACKSON, W.D., 1973: Vegetation of the Central Plateau. In Banks, M.R. (Ed.): THE LAKE COUNTRY OF TASMANIA. R. Soc. Tasm., Hobart.

Kirkpatrick, J.B., Gilfedder, L. \& Fensham, R., 1988: CITY PARKS AND CEMETERIES - TASMANIA'S REMNANT GRASSLANDS AND GRASSY WOODLANDS. Tasmanian Conservation Trust, Hobart.

MiNCHIN, P.R., 1990: DECODA: DATABASEFOR ECOLOGICAL AND COMMUNITY DATA. ANUTECH, Canberra.

Neyland, M.G., 1991: THE PTUNARRA BROWN BUTTERFLY RECOVERY PLAN: MANAGEMENT PHASE. Dep. Parks, Wildl. \& Herit., Tasm.

Nerland, M.G., 1992: The ptunarra brown butterfly, Oreixenica ptunarra, Conservation Research Statement. Sci. Rep. 92/2. Dep. Parks, Wildl. \& Herit., Tasm.

Nix, H.A., 1986: A biogeographic analysis of Australian elapid snakes. In Longmore, R. (Ed.): ATLAS OF ELAPID SNAKES OF AUSTRALIA. Australian Flora and Fauna Series 7. AGPS, Canberra: 4-15.

OrChard, A.E., 1988: A natural regions map for Tasmania. Pap. Proc. R. Soc. Tasm. 122: 47-51.

Poliard, E., 1977: A method for assessing changes in the abundance of butterflies. Biol. Conserv. 12: 115-134.

Prince, G.B., 1988: The habitat requirements and conservation status of Tasmanian endemic butterflies. Dep. Lands, Parks \& Wildl., Tasm.

SHEPHERD, R.R., 1973: Land use on the central plateau with special reference to the grazing land. In Banks, M.R. (Ed.): $T H E$ LAKE COUNTRY OF TASMANIA. Royal Society of Tasmania, Hobart.

Wells, S.M., Pyle, R.M. \& Collins, N.M., 1983: THE IUCN INVERTEBRATE RED DATA BOOK Int. Union. Conserv. of Nat. \& Nat. Resour., Gland, Switzerland. 